\title{
Competencia municipal sobre menores Y su reforma
}

por

\section{ANTONIO MARTINEZ BLANCO}

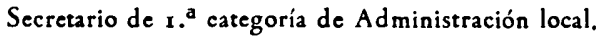

SUMARIO: I. LA COMPETENCIA MUNICIPAL SOBRE MENORES: 1. LA

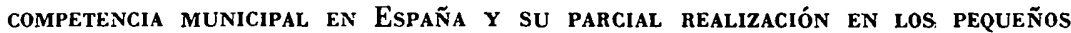

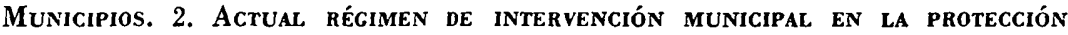
DE MENORES.-II. ESTABLECIMIENTOS MUNICIPALES DE PROTECCION DE MENORES $Y$ SUS RELACIONES CON JUNTAS $Y$ TRIBUNAIES: 1. Normativa vigente. 2. Resumen. 3. Juicio crírico.-III. LA GENERICA ACTUACION MUNICIPAL SOBRE MENORES. LAS JUNTAS LOCALES Y SU REVISION: 1. Régimen actual de las Juntas locales. 2. Hacia una re. gulación nueva de las Juntas locales.--IV. EL Pago de ESTANCias DE MENORES PROTEGIDOS POR LOS TRIBUNALES: 1. El PROBLEMA deL REPARTO DE COMPETENCIAS ENTRE ESTAdo Y MUNicipio. Las cUOTAS MUNicipales POR menores protecidos por los Tribunales. 2. El relevo de cargas estatales A los Ayuntamientos. 3. El pago de estancias de menores protegidos por los Tribunales constituye exclusivamente una obligación estatal. - V. CON. CLUSIONES.

\section{LA COMPETENCIA MUNICIPAL SOBRE MENORES}

1. La competencia Municipal eN España Y SU Parcial Realización EN LOS PEQUeños Municipios.

La competencia municipal en España es legal y prácticamente amplia, aunque suelan quedar postergados algunos de sus sectores por falta de los recursos adecuados y carencia fáctica del montaje organizativo «ad hoc» a nivel local. Se ha 
hecho la estadística de las múltiples Juntas y Comisiones que deberían funcionar a nivel local si las disposiciones legales tuvieran estricta aplicación. Son múltiples. Pero, normalmente, estas Juntas y Comisiones, si existen, es en la mayoría de los casos sobre el papel, salvo las típicamente municipales, Ayuntamiento Pleno y Comisión Permanente, cuyo funcionamiento es imprescindible, incidiendo en la directa responsabilidad del primer funcionario de la Corporación, el Secretario.

No debe, sin embargo, interpretarse este hecho en el sentido de que las obligaciones a que responden tales organismos locales no se cumplan, al menos, en su mínima y elemental expresión. Llegado el caso, el Alcalde o funcionarios llenarán el cometido ineludible de aquella competencia, al menos en los aspectos exigidos y controlados por órganos superiores.

También es verdad que las exiguas necesidades de estas pequeñas Municipalidades no exigen el funcionamiento de tantos y para ellas complicados organismos. Lo que sucede es que cada ramo de la legislación administrativa especial regula, con total ignorancia de los restantes ramos, el organismo a nivel local, Junta o Comisión, que debe llenar el contenido de la acción administrativa de que se trata. Casi siempre están presididos por el Alcalde, con diversa composición.

Porque sucede que, fruto también del olvido del legislador estatal de la variada realidad de los Entes locales, regula con absoluta uniformidad toda actividad municipal, abstracción hecha de si se refiere a la gran ciudad o al minúsculo burgo.

Llegaríamos así a la conclusión de que dos o tres Juntas o Comisiones locales podrían llenar realmente el cometido de las que hoy son decenas. Aparte, naturalmente, del Pleno, que detenta la soberanía municipal, y el órgano de gestión que es la Comisión Permanente.

Naturalmente, nos estamos refiriendo a los pequeños y aun medianos Municipios españoles que son los más numerosos, siquiera su población no sea la más cuantiosa (1).

(1) Actualmente existen en España 9.200 Municipios, de los cuales 6.700 cuentan con menos de 2.000 habitantes. Hay Ayuntamientos que tienen un presupuesto inferior al de una familia, y algunos sólo albergan a un vecino que permanece 
Es problema de difícil enfoque y solución, entrelazado con el de la deficiente Hacienda local, y con las perspectivas reformistas en pro de la creación de áreas municipales más amplias y eficientes, cual la Comarca, o la Agrupación voluntaria para servicios comunes (2).

\section{ACtual Régimen de intervención Municipal EN LA PROTECCIÓN DE MENORES.}

La protección de menores entra en la lista de competencias de los Municipios. Sabido es que el sistema español en este orden hace compatible una amplia declaración de atribución de competencia (3), con la enumeración detallada de las mismas competencias.

Pero en materia de menores la Ley de Régimen local (4) se limita a la programática declaración de ser de la competencia municipal la «beneficencia; protección de menores; prevención y represión de la mendicidad; mejora de las costumbres; atenciones de índole social, especialmente mediante la creación de Mutualidades escolares; Cotos de previsión, y albergues de transeúntes» (5).

Entonces es preciso recurrir a la legislación especial administrativa sobre la materia, constituida por dos leyes, una referida a la organización y actuación administrativa sobre menores, que en España está representada por la llamada Obra de Protección de Menores, siendo su Ley de 2 de julio de 1948,

en el término municipal para atender a una pequeña explotación agrícola o gana. dera. 336 Municipios españoles han desaparecido como Entidades locales en los últimos diez años. (Datos estadísticos facilitados por el Ministerio de la Goberna. ción, recogidos en el último número de Carta de España, publicación del Instituto Español de Emigración. Facilitado por PYRESA, Madrid, 10 de junio).

(2) La solución de Agrupaciones para servicios comunes es la estimulada últinamente por la Ley sobre modificación parcial del Régimen local, de 23 de julio de 1966.

(3) La amplitud en la declaración de competencias llega al punto de atribuir al Municipio «cualesquiera obras y servicios que tengan por objeto el fomento de los intereses y la satisfacción de las necesidades generales y de las aspiraciones ideales de la comunidad municipal» (articulo 101, k), Ley de Régimen local, texto refundido aprobado por Decreto de 24 de junio de 1955).

(4) Artículos 101 a 107 de la Ley de Régimen local, cit.

(5) Artículo 101, apartado g), de la Ley de Régimen local, cit. 
modificada por Decreto de 19 de julio de 1968; la otra, referida á los aspectos jurisdiccionales sobre los mismos, que lleva fecha de 11 de junio de 1948, y organiza los Tribunales tutelares de Menores.

Dos vertientes hemos encontrado en esta actuación administrativa a nivel local sobre protección de menores: 1) la de funcionamiento de propios establecimientos municipales de protección de menores, o contribución al pago de las estancias causadas por protegidos de los Tribunales; y 2) la genérica actuación colaboradora con el Estado a cargo, fundamentalmente, de unas Juntas locales cuya constitución se propugna con caracteres, creemos, de originalidad.

Aunque pudiera parecer paradójico comenzar criticando el excesivo número de Juntas y Comisiones locales, para acabar postulando la creación de una nueva, hoy inexistente. Pero es que partimos de la total panorámica del Derecho estatal sobre Entes locales, que no es previsible vaya a modificarse en fecha inmediata. Llegado el caso de esta revisión, que por otro lado postulamos también, la Junta Local de Protección de Menores, en estrecha relación con la de Enseñanza Primaria, y la de Beneficencia, y muy cercana a todos los aspectos de actuación social, podría quedar englobada con las mencionadas en una sola y única Junta Municipal de Atenciones Sociales y Educativas.

II. ESTABLECIMIENTOS MUNICIPALES DE PROTECCION DE MENORES Y SUS RELACIONES CON JUNTAS Y TRIBUNALES

\section{Normativa Vigente.}

La Ley de Protección de menores, organizadora de la Obra, no descarta la posibilidad de unas instituciones propias de actuación y protección por parte de los Entes locales a favor de los menores.

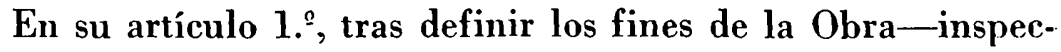
ción, vigilancia, promoción, fomento y coordinación de organismos y servicios protectores-dice que para su desenvolvimiento 
podrá relacionarse directamente con los organismos de la $\dot{A} d$ ministración central y local que tengan análoga finalidad, así como con los de Beneficencia particular.

Se atribuyen, pues, a la Obra, unas facultades superiores de dirección y suplencia en relación con la posible actuación municipal.

$Y$ caso de que no se consigan los fines de protección de menores desamparados que deben ser atendidos en razón a su situación, pondrán el caso, dice a continuación, en conocimiento de la superioridad a los efectos que procedan (artículo $1 . .^{\circ}, 4 .^{\circ}$ ).

Más específicamente, y en relación con los menores sujetos a los Tribunales tutelares, su Ley especial establece la colaboración de los Municipios ya con sus propios establecimientos, ya mediante el pago de cuotas, con arreglo al siguiente esquema :

a) Ejercicio de la facultad reformadora. Los menores confiados por los Tribunales de Menores a otras personas, familias, Sociedades tutelares o Establecimientos en el ejercicio de esta facultad, serán sustentados y educados mediante el abono de estancias sufragadas, por este orden, por: 1) sus padres, o con cargo a los bienes del menor mismo; 2 ) pensiones del Estado y Corporaciones; 3 ) los demás recursos propios de los Tribunales (artículo 25, 1).

b) Ejercicio de la facultad protectora. Los menores que el Tribunal acuerde confiar a otras personas, familias, Sociedades tutelares o Establecimientos benéficos, serán sustentados y educados, por el siguiente orden que difiere del anterior: 1) por cuenta de los Municipios en que hubieren nacido; 2) a falta de medios municipales, por las Provincias a que dichos Municipios pertenezcan (artículo 25, 2) ; 3 ) no obstante, cuando los padres o el mismo menor pudieran con sus propios recursos sufragar en todo o en parte, a juicio del Presidente del Tribunal, los gastos de educación y sustento, se abonarán a la correspondiente Corporación las pensiones que de la misma se obtengan (artículo 26, 2). Pues bien, para dar cumplimiento a este precepto, y por lo que a los Ayuntamientos se refiere, éstos, a requerimiento del Presidente del Tribunal, se harán cargo de 
los referidos menores o satisfarán los gastos de estancias (artículo 25, 2 in fine).

La diferencia de tratamiento que se observa según se trate del €jercicio de una y otra facultad, reformadora o protectora, es que en el primer caso parece que se llevaría a efecto la actuación tutelar en Establecimiento del propio Tribunal, u otro auxiliar, y haciéndose responsables del pago de estancias en primer lugar a los padres, y sólo de modo subsidiario al Estado y las que llama Corporaciones, entre las que pueden considerarse incluidas las municipales.

En cambio, cuando se trata de la facultad protectora, destacada la obligación municipal de hacerse cargo del menor, en su defecto, sufragar totalmente los gastos de sus estancias, ayudados por las Provincias, caso de insuficiencia. La elección de una $u$ otra solución parece que queda a la discrecionalidad del Presidente del Tribunal, quien, naturalmente, tendría en cucnta la existencia o no de propios Establecimientos municipales de protección.

En el caso de hacerse cargo el Ayuntamiento del menor, puede prestar este servicio utilizando sus propios Establecimientos benéficos o contratando, mediante el abono de pensiones, con entidades protectoras legalmente autorizadas o con familias honradas, pero quedando los menores protegidos bajo la vigilancia del Tribunal en todo caso, sin que puedan ser devueltos a sus padres sin autorización del mismo (artículo 26).

Nada se establece para el caso de menores protegidos por las Juntas provinciales, no estando obligados los Ayuntamientos al pago de estancias algunas, ni al acogimiento de los mismos, en virtud de disposición específica del régimen de protección de menores, aunque de tener Establecimientos propios, es lógico pensar que su obligación de acogimiento sería, tratándose de nacidos en su propio término, previa a la que pesa sobre la Junta provincial.

\section{Resumen.}

El cuadro legal de actuación de los Establecimientos municipales de menores y de los propios Ayuntamientos en su ge- 
nérica actividad sobre los mismos, en relación con los organismos de la Obra de Menores, Juntas y Tribunales, sería el siguiente:

Establecimientos municipales de protección de menores y Junta provincial.

- Corresponde a la Junta su inspección, vigilancia, promoción, fomento y coordinación.

- Puede la Junta, para ello, relacionarse directamente con los Ayuntamientos a que corresponda el nacimiento del menor.

- Puede la Junta, caso de no ser debidamente atendida, poner el caso en conocimiento de la superioridad.

Ayuntamientos y sus Establecimientos en relación con Tribunales.

- Ejercicio de la facultad reformadora del Tribunal. Es obligación de los Ayuntamientos el pago que les corresponda de las estancias causadas por los menores en los Establecimientos propios de los Tribunales o auxiliares, en defecto del pago de los padres o con cargo a bienes del menor, y en colaboración con el Estado, otras Corporaciones y recursos propios del Tribunal.

- Ejercicio de la facultad protectora del Tribunal. El Ayuntamiento debe hacerse cargo del menor a requerimiento del Tribunal, utilizando sus 'propios Establecimientos o contando con otros auxiliares; en su defecto, debe satisfacer los gastos de estancias, pudiendo resarcirse de los padres, o bienes del menor si los tiene.

3. Juicio CRítico.

No parece que la claridad haya presidido la redacción de este cuadro de relaciones y obligaciones de Ayuntamientos con Juntas y Tribunales. 
Además, ha sucedido que las Juntas provinciales se han hecho cargo de los internados por orden de los Tribunales en el ejercicio de la facultad protectora, según acuerdo del Consejo Superior en Circular de 29 de mayo de 1967. Al no tener los Ayuntamientos, por regla general, las adecuadas instalaciones para hacerse cargo de ellos, ni haberlas como auxiliares organizadas por la sociedad, estos menores quedaban a cargo del Tribunal pagando los Ayuntamientos una cuota por estancia, no muy elevada. Pero no disponiendo tampoco los Tribunales de los adecuados Establecimientos para la debida separación de los sometidos a las facultades protectora o reformadora, el Consejo Superior adoptó el acuerdo de referencia. Por otra parte, parece lógico que la acción protectora de los Tribunales se ejerza a través de las Juntas, órganos específicos de asistencia social, puesto que además, unos y otros, son secciones de un mismo organismo y Obra, el Consejo Superior.

De todas formas sería de desear que esta regulación se clarificara y sistematizara en normas de fácil inteligencia y más depurada técnica. Sin perjuicio de dictarse las oportunas instrucciones de detalle que divulgaran estas ideas entre autoridades locales y funcionarios directivos, estimulando una actuación más intensa, en la que seriamente se ha pensado. Este podría ser el mejor fruto de la conmemoración que celebramos del 50 aniversario de la creación de los Tribunales de Menores (6).

(6) Estadistica de Establecimientos municipales de protección de menores.

No son muchos los Municipios que cuentan con propios Establecimientos de protección de menores. Incluso su actuación en tal sentido suele encuadrarse dentro de la asistencia social municipal, como servicio municipal de asistencia benéficosanitaria, en cumplimiento del artículo 102, i) de la Ley de Régimen local, que impone como mínimo a todo Municipio la obligación del servicio de asistencia médico-farmacéutica a familias desvalidas.

Naturalmente que sus Asilos, Hospicios y Hospitales municipales, donde los hay, suelen atender a los niños desamparados a falta de instituciones específicas y en tanto no dispone de los mismos la Junta o el Tribunal correspondiente.

Hemos recogido aqui tan sólo las instituciones especificas de protección y acogimiento de menores a cargo de los Municipios:

Barcelona:

- Hogar Preaprendizaje número 2 «Ciudad de los Muchachos», para asistencia social con prestación de enseñanza primaria. Carretera de La Rabasada, sin número. Barcelona. Teléfono 2475699.

La Coruña:

- Residencia municipal de Nuestra Señora del Rosario, para formación y 
educación de niñas pobres del Municipio, cursándose enseñanza primaria, formación profesional y escuela-hogar. Juan Canalejo, 12, La Coruña. Teléfono 21677.

- Colegio Santa Teresa de Jesús, con finalidad benéfico-docente, cursándose enseñanza primaria. Méndez Núñez, 11, El Ferrol del Caudillo (La Coruña). Te. léfono 1630.

\section{Guipúzcoa:}

- Santa Casa de Misericordia de Azcoitia, con funciones benéficas diversas, prestándose enseñanza primaria y bachillerato. Julio Urquijo, 2. Telëfono 81323.

\section{Lérida :}

- Real Casa de Caridad o Misericordia de Cervera, para acogimiento y enseñanza de menores de catorce años. Calle Mayor.

\section{Madrid:}

- Colegio Municipal de San Ildefonso, para internado de huérfanos, cursando enseñanza, formación profesional y bachillerato. Alfonso VI, 1. Teléfono 2653454.

- Internado femenino Palacio Valdés, para enseñanza de huérfanas en régimen de internado. Paseo del Prado, 38. Teléfono 2273692.

- Colegio Nuestra Señora de la Paloma, para internado de huérfanos de Madrid, cursándose enseñanza primaria. Los Colegios, 2. Teléfono 309. Alcalá de Henares.

- Asilo de la Caridad de Aranjuez, para recoger ancianos y niños pobres del pueblo, con prestación de enseñanza primaria. Rey, 1. Teléfono 303.

- Colegio.Internado de Nuestra Señora de la Paloma (depende del Ayuntamiento de Madrid), benéfico-docente, con prestación de enseñanza primaria y bachillerato. Avenida Francisco Ruano, 8. Teléfono 56. Cercedilla.

- Internado Palacio Valdés (Ayuntamiento de Madrid), con finalidad docente en régimen de internado. Tres Cantos (Colmenar Viejo). Teléfono 126.

Murcia:

- Casa de Misericordia de Cartagena, para beneficencia local. San Diego, 17. Teléfono 1346.

Navarra:

- Casa de Misericordia del Valle de Baztango (Elizondo). Santiago, 2. Telé. fono 48.

- Hospitalillo de niños huérfanos de Tudela, para recogida de niños huérfanos. Pedro Ortiz, 44-46.

- Real Casa de Misericordia de Tudela, para recogida de niños huérfanos. Misericordia, 2. Teléfono 83.

\section{Vizcaya:}

- Hospital.Asilo de Santurce.Antiguo, para acoger ancianos enfermos y niños. Primo de Rivera, 20. Teléfono 253520.

- Residencia municipal Sagrado Corazón, de Guecho, para acoger huérfanns y ancianos. Alango, 3. Teléfono 278204.

\section{Zaragoza:}

- Casa Amparo, para asilo de ancianos y niños. Predicadores, 96. Teléf. 221994.

Las Diputaciones provinciales vienen obligadas; como competencia mínima, al sostenimiento de Casa Maternidad, Hogares Infantiles (Casa de Expósitos, Hogar de Huérfanos y Desamparados y Casas de Misericordia), según el artículo 24.5 de la Ley de Régimen local. Merced a unos más amplios recursos, desarrollan en este aspecto una notable labor. Por los menores del Municipio acogidos en tales Fstablecimientos no se abona cuota alguna.

Hemos tomado los datos que se exponen de la obra de Ramón Martín Mateo. Guia de Actividades Públicas Asistenciales. La asistencia social como servicio pú 


\section{LA GENERICA ACTUACION MUNICIPAL SOBRE MENORES. LAS JUNTAS LOCALES Y SU REVISION}

\section{Régimen actual de las Juntas locales (7).}

Con independencia de la existencia o no de propios Establecimientos municipales de menores, el Ayuntamiento debe realizar en todo caso una labor general de protección de menores, de signo fundamentalmente colaborador.

El Título II de la Ley de Protección de menores está dedicado a las Juntas de Protección de Menores, pero cuando el técnico municipal busca la lógica referencia a las Juntas municipales que de aquel enunciado cabría esperar, es muy poco lo que encuentra, y generalmente sin aplicación.

En primer lugar, las Juntas locales vienen configuradas como excepcionales, pues su constitución no es obligada y necesitan la autorización del Consejo Superior en aquellas localidades en que lo considere oportuno, pues tienen jurisdicción independiente de las Juntas provinciales (artículo 40,2).

Cuando fueren autorizadas estarán integradas por (artículo 40,2$)$ :

blico, Madrid, 1967. Ministerio de la Gobernación. Colección Documentos, pági. nas 333 y siguientes.

( 7 ) Después de redactado este trabajo se ha dictado el Decreto de 11 de. julio de 1968, que modifica algunos artículos del texto refundido de Protección de Menores de 2 de julio de 1948, y que con gran paralelismo respecto de las opinio. nes aquí sustentadas, lleva a cabo, en el aspecto que nos ocupa, las siguientes reformas:

1) Suprime las Juntas locales de Protección de Menores existentes en la actualidad, que pasan a integrarse en la Provincia respectiva, aunque subsisten las que radiquen en lugares donde existan Secciones de Tribunales tutelares de Menores, y ello con su misma organización actual (artículo $2 .^{\circ}$ ).

2) Al mismo tiempo se regula la posibilidad de que la Comisión Permanente del Consejo Superior, oída la Junta provincial respectiva, pueda crear Delegaciones locales a los simples efectos del ejercicio de la protección en aquellas localidades que considere necesario y oportuno (artículos 40,27 a, y 53 j).

En definitiva se viene a establecer la posibilidad de crear un organismo local, auxiliar de las Juntas de Protección de Menores radicadas en las capitales de Provincia, con acierto denominado «Delegación», y no Junta, para no confundirlo con las anteriores Juntas de jurisdicción independiente, y para expresar ésta su finalidad de simple cooperación a los fines de protección de menores sin jurisdicción propia. 
Presidente:

el Alcalde.

Vocales natos:

el cura párroco de superior categoría.

el médico más antiguo.

el juez de Primera Instancia, o el municipal o el comarcal.

el maestro de más antigüedad.

la maestra de más antigüedad.

el representante local del Sindicato del Espectáculo.

Vocales elegidos (por el Consejo Superior a propuesta de la Junta provincial respectiva) :

una madre de familia.

un padre de familia.

un obrero.

Sólo otro precepto se refiere específicamente a las Juntas municipales. En el artículo 56, a propósito de regular el cometido de la Sección 2. (Asistencia Social) de las Juntas provinciales, y después de decir que la protección se ejercita bajo la directa inspección del Presidente de la Junta o Vocal que éste designe, y que las facultades atribuidas al Presidente de la Junta se refieren al Presidente efectivo de las Juntas provinciales, aclara que «en las Juntas locales estas facultades se atribuyen al juez de Primera Instancia y, donde no lo hubiere, al juez municipal o comarcal».

Aunque con una interpretación analógica pudieran aplicarse algunos preceptos reguladores de las Juntas provinciales, la verdad es que esta regulación es parca e insuficiente. En una próxima revisión de tal régimen, dentro del marco del llamado Derecho especial de menores, debieran tenerse en cuenta estas deficiencias.

Sobre la subsistencia de las actuales Juntas locales exentas, que son escasas en número (El Ferrol, Cartagena, Gijón, Cá- 
diz ...), serán la experiencia y criterio del Consejo Superior los que deben decidir. No entramos en ello. Nosotros postulamos, por el contrario, la creación de nuevas Juntas locales en todos los Municipios, pero con un signo totalmente distinto.

\section{Hacia una regulación nueva de las Juntas locales.}

Queremos destacar la trascendental importancia de una directa actuación municipal de base. Si el mantenimiento de propios Establecimientos no es posible para la inmensa mayoría de Municipios, ni cuentan con el personal o la tradición adecuados para ello, sobre todo cuando en la actualidad crece el cúmulo de obligaciones municipales en torno a servicios de gran trascendencia social y envergadura económica, que son de más directa vinculación a los estrictos fines de la convivencia vecinal, no es posible pedir a todos los Municipios la creación de tales Establecimientos.

Pero hay otra labor más sencilla, al par que más necesaria y trascendental si cabe, que todo Ayuntamiento puede realizar en mejores condiciones que nadie.

Es una misión de colaboración con la Obra de Protección de Menores, concretada en las siguientes competencias:

1) Investigación e informe sobre los daños, explotaciones a delitos de que los menores puedan ser objeto.

2) Recogida e internado en los Establecimientos de la Obra, o de Diputaciones, Cáritas, Auxilio Social o privados, de los menores abandonados, perfectamente localizados y controlados en todo su término municipal.

3) Atención a los menores que han cumplido condena, cuidando de que reciban formación y educación, mediante su internamiento en los mencionados Establecimientos, si no los atendieran sus propios padres.

4) Persecución de las faltas o delitos cometidos por menores, facilitando a los legitimados procesalmente la información necesaria, o asumiendo directamente el ejercicio de la acción.

Por la proximidad a las necesidades, conocimiento del medio social, ascendiente vecinal y continuada vigilancia sobre estos 
aspectos, las Juntas locales debieran ser imprescindibles auxiliares de la Obra de Menores.

Con este carácter de auxiliares de las Juntas provinciales y no sustitutivas de las mismas, y desde luego, con la índole de obligadas y no como privilegio excepcional, debieran configurarse unas nuevas Juntas locales a la hora de revisar la Ley de Protección de menores.

Si a estas Juntas locales se les diera un cáracter vivo y eficaz, por medio de un contacto periódico (Asamblea provincial anual) entre ellas y las provinciales, para mutuo estímulo, aclaración de directrices, conocimiento de los resultados obtenidos, etc., se habría adelantado mucho, contando con una mayor suficiencia de medios asistenciales por parte de las Juntas provinciales, para lograr la meta de que no exista un solo menor abandonado, explotado o delincuente sin la necesaria y justa asistencia social.

\section{EL PAGO DE ESTANCIAS DE MENORES PROTEGIDOS POR LOS TRIBUNALES}

1. El problema del reparto de competencias entre Estado Y Municipio. Las cuotas MUNicipales por MENORES PRotegidos por los Tribunales.

El tema del reparto de competencias Estado-Entes locales es problema siempre candente por ser manifestación del más amplio de las relaciones entre aquéllos, dotados ambos de originalidad.

Sabido, por otro lado, es que más que de listas de exclusivas competencias, hay una cuestión de distribución de las mismas.

En el caso concreto de la protección de menores es evidente que deben hacer acto de presencia Estado y Corporaciones locales. Pero ¿hasta qué punto y medida?

Parece evidente que por la misma naturaleza de las cosas es incumbencia estatal aquella inspección, dirección y coordina. ción que representa la labor del Consejo Superior de Menores. Y que es típicamente municipal, como de «jure condendo» hemos postulado, la colaboración consistente en la labor inspectora y 
protectora a nivel local con estricta dependencia de las Juntas provinciales. Aún más. Si la iniciativa privada está llamada al sostenimiento de instituciones auxiliares $y$, si hemos de creer en el principio de la subsidiariedad, parece también evidente que es preciso reconocer a los Municipios el derecho a organizar sus propios Centros de protección educadora sobre menores abandonados de su término. En cuanto a las Diputaciones provinciales, este derecho constituye por mandato legal una obligación mínima.

El problema se plantea concretamente en cuanto al pago de las cuotas por el mantenimiento de menores protegidos por Juntas y Tribunales. $Y$ en realidad con relación tan sólo a los acogidos por los Tribunales de Menores. Sabemos que, actualmente, los Ayuntamientos del lugar de residencia o naturaleza del menor y las Diputaciones provinciales, en su caso, deben satisfacer la cantidad complementaria que se estime por estancias, que por ahora se fija en cinco pesetas por día y menor (8). Efectivamente, la Ley de Tribunales tutelares establece que los menores que el Tribunal acuerde confiar a otras personas, familias, sociedades auxiliares o Establecimientos benéficos en el ejercicio de las facultades protectoras serán sostenidos y educados por cuenta de los Municipios en que hubieren nacido... (artículo 25, 2), y que los menores confiados por el Tribunal a tales personas, sociedades o Establecimientos en el ejercicio de la facultad reformadora, serán sustentados y educados mediante el abono de estancias sufragadas por sus padres, o con cargo a los bienes del menor, o con las pensiones del Estado o Corporaciones... (artículo 25$)$.

(8) «Los gastos de los internamientos de los menores protegidos por el Tribunal tutelar, de los que se han hecho cargo las Juntas, deben zer sufragados con las cantidades que los Tribunales tutelares de Menores perciban de las nóminas de estancias que anualmente formulan del fondo del Estado y las que perciben del fondo benéfico-social-a más de las percibidas de las Corporaciones locales-, que son de cinco y diez pesetas por menor y día respectivamente, que son notoriamente insuficientes» (Circular del S. S. de Protección de Menores de 29 de marzo de 1967). 
2. El relevo de cargas estatales a los Ayuntamientos.

En estrecha conexión con el tema de las competencias estatal y municipal y su adecuado reparto, está el movimiento legal y doctrinal, partidario del relevo a los Ayuntamientos de las que se consideran «cargas» para ellos, pues constituyendo contenido de la misión propia del Estado, deben pasar al mismo como sus típicas obligaciones.

La última expresión legal de esta tendencia la constituye el artículo 23 de la Ley 48/1966, de 23 de julio, sobre reforma del Régimen local, que dice:

«Para la efectividad de lo dispuesto en la Base primera de la Ley de 17 de julio de 1945, sobre el relevo de las obligaciones que tengan por objeto costear, subvencionar o realizar servicios de la Administración general que actualmente puedan pesar sobre las Corporaciones locales, se procederá a desgravar a dichas Corporaciones de aquellas atenciones desde el 1 de enero de 1968».

El artículo 19, Subvenciones, párrafo $4 .^{\circ}$, de la misma Ley, dice:

«En ningún caso podrán exigirse aportaciones con carácter forzoso a Corporaciones locales que no se ajusten a lo prevenido en los apartados anteriores, salvo las previstas expresamente en la Ley de Régimen local, en la de 8 de septiembre de 1941, de creación del Instituto de Estudios de Administración Local y el artículo 101 del Reglamento de Pósitos, de 14 de enero de 1955».

Los antecedentes de estas disposiciones hay que buscarlos en la Base primera de la Ley de 17 de julio de 1945 (último párrafo); en la Base adicional cuarta de la Ley de 3 de diciembre de 1953; Disposición adicional segunda del Decreto de 18 de diciembre de 1963; artículo 9. de la Ley de Régimen local; artículo 179 del Reglamento de Haciendas locales; número 30 de la Orden de 31 de julio de 1959, y Decreto-ley de 12 de marzo de 1954 (9).

(9) Ver Abetra, Reforma del Régimen local. El Consultor de los Ayuntamientos. Madrid, 1966. 
3. El pago de estancias de menores protegidos por los Tribunales GONSTITUYE EXCLUSIVAMENTE UNA OBLIGACIÓN ESTATAL.

El criterio adecuado al enfrentarse con la cuestión de cargas de los Entes locales no es el de pretender relevar al Ayuntamiento del mayor número de obligaciones actuales, de las conexas con la simultánea y paralela acción estatal, sino el discernir entre lo que sea «carga», gravamen, servidumbre sobre el Municipio a favor del Estado, de lo que sea genuina obligación municipal, capacidad y competencia del mismo, aunque por la escasez de recursos no pueda atenderlos debidamente. Porque en este último supuesto lo procedente sería no suprimir la obligación, sino dotar al Ayuntamiento de los medios económicos precisos (10).

Ahora bien, ¿las estancias de menores residentes o naturales del Municipio protegidos por Tribunales, deben ser sufragadas sólo por el Estado, o deben participar en su pago los Ayuntamientos?

Haciendo abstracción del deficiente estado de las Haciendas locales, y con una perspectiva objetiva e imparcial, parece que si el Estado monta, en ejercicio de facultades y derecho propio, un sistema de Tribunales con facultades reformadoras y protectoras de asistencia y educación, es el propio Estado el que debe sufragar los gastos que ello ocasione (11).

Sólo podría militar a favor de una participación municipal en el abono de tales cuotas, la consideración moral de que por este procedimiento el Ayuntamiento podría tomar conciencia

(10) De este mismo planteamiento hemos partido ante la obligación municipal de aportar determinadas cantidades a los Pósitos, o de aportación de solares y subvenciones para construcciones escolares («Actividad crediticia de los entes locales con fines agrícolas», R. E. V. L., núm. 159, páginas 337 y siguientes; «Las obligaciones o «cargas» de los Ayuntamientos en torno a la enseñanza primaria», Cer. tumen, núm. 316, 1968, páginas 190-193).

(11) En una «Relación provisional de cargas por servicios de la Administración general del Estado que pesan actualmente sobre las Corporaciones locales, y de las que éstas deben quedar relevadas desde 1 de enero de 1968 (artículo 23 de la Ley 48/1966, de 23 de julio)», remitida a los Ayuntamientos para confección €stadistica del montante económico de tales cargas, figura en el apartado del Ministerio de Justicia, el «pago de estancias de acogidos en Tribunales tutelares de Menores». 
de los menores de su término protegidos por el Tribunal, de lo que quizá no tendría noticia, o ésta sería muy vaga.

Pero si hemos de crear y vitalizar Juntas locales en todos los Municipios, conscientes de su misión colaboradora, pero esencial, en orden a la inspección y protección de menores, Juntas que hoy no existen legal ni prácticamente, este último argumento pierde gran parte de su valor.

Si verdaderamente estuvieran sometidos a protección del Tribunal todos los niños más o menos abandonados que hoy existen, el pago por ahora de cinco pesetas por día y menor, puede llegar a suponer en su día cantidades importantes, pues tal cuota, hoy verdaderamente exigua, debería ir, lógicamente, en progresivo aumento, como razones de humanidad y decoro exigirian para el digno mantenimiento de unos servicios adecuados de protección, asistencia y educación del menor abandonado (12).

Pero con frecuencia las autoridades municipales se encuentran con dificultades a la hora de internar en Establecimientos adecuados a menores moralmente abandonados, por falta de plazas. En muchas localidades se plantea el problema de menores cuyos padres, si los tienen, hacen caso omiso o no pueden cumplir los deberes de guarda y educación de sus hijos. Normalmente, estos menores realizan pequeñas conductas delictivas por las que son enjuiciados por los Tribunales de Menores, volviendo, una vez cumplida la condena, al mismo género de vida callejera, vagabunda y socialmente peligrosa, constituyendo un verdadero quebradero de cabeza para Alcaldes, Guardia Civil y Policía urbana.

Sin duda tiende a solucionar este problema el actual movimiento de interés por el menor, su protección y su Derecho, un Derecho, se dice, especial. Interés del que son prueba las

(12) En un Municipio rural de 12.000 habitantes, como Alhama de Murcia, y según informes verbales del Juzgado de Paz, hay dieciséis niños sin asistencia de facultad protectora-reformadora, a pesar de las gestiones realizadas por las autoridades cerca de todos los organismos competentes. Hay tres niños acogidos a la Obra de Protección de Menores. Y hay que decir que la actuación del Tribunal de Menores de la Provincia (cuya presidencia, valga la digresión, recae para honra de los Cuerpos Nacionales en el Jefe del Servicio de Inspección) es eficacísima. Pero faltan plazas, es la explicación. 
«I Jornadas Hispánoamericanas en torno al Derecho especial del menor» (1968), organizadas por el Instituto de la Juventud en colaboración con el Instituto de Cultura Hispánica. Así como el reciente ciclo de conferencias organizado por la Real Academia de Jurisprudencia y Legislación sobre el tema general de «La política de la juventud como premisa insoslayable de un nuevo Derecho: el Derecho del menor», conmemorativo del 50 aniversario de la creación de los Tribunales tutelares de Menores.

En la construcción de este nuevo Derecho especial no debe estar ausente la perspectiva de las Corporaciones locales. Contribuir a construir este Derecho del menor, desde el punto de vista de su protección a nivel administrativo local, es lo que ha pretendido este trabajo, fruto de la diaria práctica de una profesión en estrecho contacto con las realidades locales, sus deficiencias y su grandeza.

\section{CONCLUSIONES}

1. ${ }^{2}$ La experiencia acredita que existen actualmente en España gran número de menores moralmente abandonados en mayor o menor medida, sin que reciban la protección y ayuda educacional a que tienen derecho, a pesar de la labor amplia y eficaz, pero insuficiente, de la Obra de Protección de Menores, secundada por la labor social pro infancia de Diputaciones provinciales, Auxilio Social, Cáritas, Iglesia e iniciativa privada.

Para remediar esta situación, y aparte de la intensificación de las inversiones estatales, es preciso despertar la conciencia social de colaboración, especialmente de las Corporaciones Jocales.

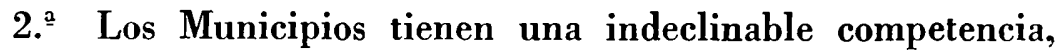
derecho y obligación, que es reconocida y meramente enunciada por la Ley de Régimen local, en la protección de menores. Poner a punto su estatuto jurídico, reglamentando su fáctico y eficaz funcionamiento, es deber de la hora presente.

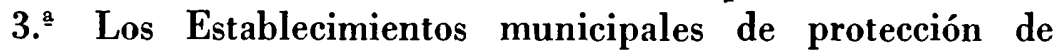


menores, aunque escasos en número, constituyen un derecho y una eficaz manifestación de aquella competencia municipal.

4. ${ }^{a}$ El cuadro legal de relaciones entre Municipios y Obra de Menores (Juntas provinciales y Tribunales de Menores) no está suficientemente explicitado, es confuso y poco conocido. Serían necesarias unas directrices y normas de estímulo y recordatorio, más claras, precisas y sugeridoras a este respecto.

5. ${ }^{-}$Si las actuales Juntas locales de Protección de Menores, exiguas en número y cuya desaparición se prevé (13), tienen un carácter de jurisdicción exenta de las provinciales $\mathrm{y}$, por lo tanto, son excepcionales y otorgadas, deberían regularse unas Juntas locales de nuevo cuño, con carácter obligatorio en todos los Municipios, pero con función esencialmente colaboradora con la Obra estatal de Menores.

6. ${ }^{a}$ Ante la complejidad y elevado número de Juntas y Comisiones locales de toda índole, fruto de un Derecho de la Administración estatal para las Corporaciones locales, hecho compartimientos estancos, las nuevas Juntas locales de Protección de Menores que se propugnan integrarían, en una futura revisión del Régimen local, unas Juntas Jocales de Asistencia Social y Educación, junto con las actuales de Beneficencia, Enseñanza Primaria, de Patronato Escolar, de Patronato de Protección de Plantas y Animales, de Sanidad, de Juventud, etc.

7. ${ }^{\text {a }}$ Unas Asambleas provinciales de Juntas locales constituirían medio adecuado para la puesta a punto de una campaña nacional de estímulo de la actuación local en la protección de menores.

8. ${ }^{a}$ En el actual momento doctrinal y legal existe una tendencia a liberar a las Corporaciones locales de las «cargas» por servicios de la Administración general del Estado que pesan sobre aquéllas. Entre tales cargas figura el pago de estancias por

(13) El nuevo Decreto de 11 de julio de 1968 responde en parte a esta misma crientación al regular la posibilidad de crear Delegaciones locales de las Juntas provinciales de Protección de Menores. No las establece como obligatorias, sino cono potestativas de la Comisión Permanente del Consejo Superior (artículo 40. modificado), pero en todo caso desaparecen como posibilidad general las Juntas locales de Protección de Menores actuales con jurisdicción independiente, y las nuevas Delegaciones tienen la misión a que responde su nombre, colaborar con las Juntas provinciales. 
menores acogidos por Tribunales de Menores, que viene actualmente impuesto por la Ley de Tribunales de Menores.

Sin renunciar a una específica actuación municipal en la Obra de Menores, que postulamos, parece que los Ayuntamientos deben ser relevados de tal «carga». 